\title{
Single Molecule Force Spectroscopy Studies of Missense Titin Mutations That Are Likely Causing Cardiomyopathy
}

\author{
Jiacheng Zuo, Denghuang Zhan, Jiahao Xia and Hongbin Li* \\ Department of Chemistry \\ University of British Columbia \\ Vancouver, BC V6T 1Z1 \\ Canada
}

\section{Supporting Information}

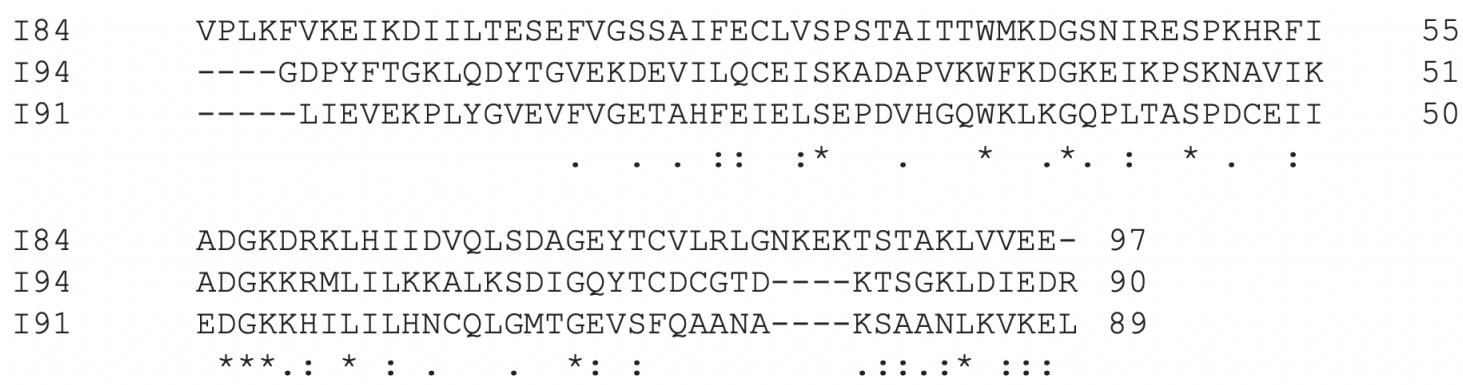

Figure S1. Sequence alignment of I84, I94 and I91.

Table S1. Chemical denaturation parameters

\begin{tabular}{|c|c|c|c|}
\hline & $\Delta \mathrm{G}(\mathrm{kcal} / \mathrm{mol})$ & $\mathrm{M}\left(\mathrm{kcal} \mathrm{M}^{-1} \mathrm{~mol}^{-1}\right)$ & {$[\mathrm{D}]_{1 / 2}(\mathrm{M})$} \\
\hline $\mathrm{I} 94$ & $2.86 \pm 0.10$ & $2.44 \pm 0.06$ & $1.17 \pm 0.0$ \\
\hline R57C-I94 & $1.68 \pm 0.05$ & $2.48 \pm 0.07$ & $0.68 \pm 0.01$ \\
\hline I84 & $5.67 \pm 0.18$ & $1.95 \pm 0.06$ & $2.90 \pm 0.01$ \\
\hline S22P-I84 & $4.80 \pm 0.13$ & $2.07 \pm 0.05$ & $2.32 \pm 0.01$ \\
\hline
\end{tabular}

